\title{
Research on the Integration of Literary Education into College English Class from the Perspective of Research-Based Learning Strategy
}

\author{
Shiyu Zhou \\ School of Foreign Languages \\ China University of Geosciences (Wuhan) \\ Wuhan, China \\ dakejuinf@163.com
}

\author{
Yingxian Zhang \\ School of Foreign Languages \\ China University of Geosciences (Wuhan) \\ Wuhan, China \\ yingxianz@163.com
}

\begin{abstract}
The aim of this study is to improve students' research-based learning ability and establish a new type of effective student-centered teaching model for college English education with the help of English classic reading. English literary education is an essential part of college English class. By analyzing the advantages of integrating English classic reading into college English education and the status-quo of current literary education in college English class, this paper points out that the integration of literary education into college English class not only improves students' language proficiency in an allround way but also helps students cultivate the strategy of research-based learning. This paper also suggests the practical application of literary education in college English teaching: college English teachers can recommend classics which meet student's English abilities, appropriately combine college English textbooks with literary elements and design teaching activities related to literature and establish a long-term reading evaluation mechanism.
\end{abstract}

Keywords-College English Education in China; Literary Education; Research-Based Learning; Cooperative Learning

\section{INTRODUCTION}

In the book Literature and Language Learning co-edited by Christopher J. Brumfit and Ronald A. Carter, twenty famous experts and scholars explain their different opinions in language teaching and literature research. But in terms of the relationship between literature and language, they reached a consensus: literature is the art of language and language is a special medium and expression tool of literature [1]. With the development of modern science and technology, our requirements for students' English language, especially the ability of reading and writing science and technology literature, have gradually improved, and the practical training mode in college English education has become a trend. However, literature education has rarely been mentioned. In practice, college English teaching is almost equivalent to language skill training as more emphasis is placed on the teaching of language knowledge and the cultivation of language skills; moreover, due to the heavy teaching tasks and limited class hours, the utilitarian motivation of students' English learning is obvious. Consequently, teachers easily ignore the role of literature education in the practice of college English teaching.

Supported by "the Fundamental Research Funds for the Central Universities of CUG (Wuhan)” CUGW170814 and CUGW180811
Many students, even if they successfully pass English examinations, still lack basic literary knowledge and the ability to use English for cross-cultural communication.

Apart from improving students' language proficiency in an all-round way, the integration of literary education into college English class also helps students cultivate research-based learning strategy. Stern points out that learning strategies are the general trend or general feature of the methods used by language learners [7]. English learning strategies involve the following characteristics: learning strategies are the methods and means adopted by English language learners to improve the ability of second language/foreign language; learning strategies run through the whole process of language learning and language use and they are driven by problems and serve to solve obstacles in language activities; learning strategies are flexible and diverse, and can be influenced by many factors; learning strategies can be either explicit external behaviors or implicit psychological activities; learning strategies can be trained and learned. In summary, the learning strategy is an instinct and language learners can automatically obtain some basics through the innate problem-solving mechanism or strategic acquisition device (SAD). Most language learners use learning strategies intentionally or unintentionally without any strategic training, so do college students in English classrooms. Consequently, practicing effective learning strategies are essential for college English education and should be taught and trained in college English class.

Among a variety of language learning strategies, Stern proposes that research-based learning is not only a new way of learning but also an advanced educational thought and teaching method [7]. It aims to cultivate, enhance and sustain thoughtful and active learning based on learners' analytical skills and teamwork. Research-based learning emphasizes students' independent participation in learning activities in a similar way to that in scientific research. Students are expected to act as participants in the research process and problem-solving inquiry. According to Stern, for language learners, this learning strategy can develop both academic knowledge and analytical skills such as problem identification, research design, data collection and analysis. Learners are involved in the entire process of research including processes like "literature review, observation, hypothesis formation, research design, data 
collection and analysis, results and discussion, report drafting" [7]. Therefore, students can gain hands-on experience and gradually become adept at questioning, willing to explore and strive for knowledge, and their desire to explore and innovate can be cultivated in the meantime. The characteristics of research-based learning such as autonomy, openness and inquiry are conducive to cultivating students' creative reading ability and critical thinking habits in the teaching process, which is an effective way for students to improve their understanding about literary works. On the other hand, the abilities demanded by research-based learning are strengthened in the process of reading. In conclusion, research-based learning and literature reading are interrelated.

In college English teaching, research-based learning, on the one hand, reflects the students' creative reading of the text. This is a process of utilizing imagination and creativity and finally the creative criticism in which the students explore the aesthetic factors such as the characters, themes and verbal forms of the text, and develop their own opinions. On the other hand, research-based learning guarantees that in the process of teaching students will not passively accept but actively explore, thus reflecting learners' autonomy. The exposure to English classics is not only a prerequisite for students to practice language and form original insights, but also meets the requirements of individualized education and individualized development [3].

In addition to the literary materials discussed by teachers and students in the classroom, students can also select English works they are interested in and conduct an in-depth reading. Certainly, literary education is not limited to English classroom teaching, but should be integrated into the student's life. Students can develop good reading habits, develop new thinking patterns and study independently.

\section{THE STATUS QUO OF LITERARY EDUCATION IN COLLEGE ENGLISH TEACHING}

As one of the essential parts of higher education, literary education should occupy a place in college English class. However, English classes in most universities in China are guided by various examinations. The content of the course is mainly based on language skill training, highlighting the practice of listening, speaking, reading and writing skills, but tends to ignore the importance of literature in language study. For instance, a large amount of college students, even English teachers, see the practice for CET 4 and 6 as the major aim of college English classes. Furthermore, although most of the college English textbooks used in China are carefully selected from the original reading materials which have both beautiful language and profound meaning, those reading texts have been greatly reduced and thus lost the charm of the classic works in order to meet the needs of classroom teaching. Thirdly, some English teachers tend to take vocabulary and grammar as the priority in English teaching and divide the articles into fragments so that they turn the pleasing reading experience into a boring input. It is difficult for students to have an overall grasp of the articles, not to mention the appreciation of literature.
College English teaching in China has one-sided emphasis on the training of basic language skills for a long time, while ignoring students' ability to understand literary and cultural backgrounds. As a result, students tend to lack both qualified language skills and an understanding of Western culture. Consequently, college English teachers must re-examine the content of our teaching, not only the courses aimed at language abilities, but also the courses of teaching western culture and even comparative studies in English, in order to cultivate students who are able to possess both excellent language skills and independent thinking.

A large number of students have already realized the necessity of studying literature in college English class, as well. In an investigation of non-English majors in a key university in central China, nearly $70 \%$ of a total of 500 undergraduate students participating in the survey expressed their interest on English literature and culture. The interviewees are selected from undergraduates in this university, from the second to the fourth year. On the one hand, those students claimed that reading English literature is beneficial for language learning; on the other hand, nearly half of those students did not even have the most basic literary knowledge. When talking about Literature education in college English teaching, nearly $90 \%$ of students expressed their expectation for containing literature reading in class [4]

\section{APPLICATION OF LITERARY EDUCATION IN COLLEGE ENGLISH TEACHING}

Professor Zhang Longxi has given a definition for literature in college English teaching: "Literature here should be understood broadly as exemplary and important texts that demonstrate what good English is and train the students to think and reason logically". He firmly believes that the best way for students to learn a foreign language is by reading its literature and the reason for that is very simple: "the most effective, powerful, and beautiful expressions in a language are often found in its literature.” [8] Since reading literary classics in English may be a quite challenging task for Chinses undergraduates from non-English majors, college English teachers should be extremely careful about designing teaching procedures and guiding students to practice research-based learning strategy. The teachers must take efforts to choose proper literature works for reading tasks, consider the way to integrate literature into college English textbooks and finally establish an effective evaluation system based on students' English reading.

\section{A. Recommend Classics that Meet Student's English Abilities}

For most English learners, especially the non-English majors in science and engineering colleges, due to limited English reading, they are not confident in reading British and American classics. Therefore, college English teachers must take students' English level into consideration and recommend the works in an authentic language that students are willing to read. For instance, the author recommends simple and abbreviated English novels to freshmen who have just encountered British and American works, such as the famous Oxford Bookworm series. As most freshmen have heard or read Chinese translation version before, making full use of 
students' familiarity with such works can remove their resistance to English reading and cultivate their interest in Western culture.

After the students already have acquired some reading foundation, from the second semester the teacher can select some English works which are not very challenging and encourage students to read a book and write an English book report every semester with the help of the dictionary. Once decided which book to read, the students are required to make a short presentation in class to introduce some basic information like the background, theme and major characters of the story. They also need to explain why they choose the book for reading in that semester. In order to give an effective presentation, the students will search online and look up in school library. Taking efficiency into consideration, they usually work in groups and cooperate with several partners. As a consequence, they are able to practice both research skills and teamwork spirit while doing the literature-related task. Books based on beautiful fairy tales and short stories adapted from movies or cartoons are the most popular among young students, such as Flipped, Peter Pan, Harry Porter and The Great Gatsby. These English books are time-tested classics which introduce Western social background, customs, religious beliefs, etc., and therefore can enhance students' interest in language and culture. In order to better understand the books they are reading, a lot of students will actively search for audio books, TV series, movies and dramas adapted from the original stories, which not only improves their reading ability but also comprehensively improves language proficiency.

\section{B. Appropriately Combine College English Textbooks with Literary Elements}

In China, reading textbooks used in college English teaching are mostly divided into units, with each unit organized around a certain theme. Teachers can appropriately select literary materials as supplements according to the theme of the unit. For example, adapted films and English poems related to the unit theme can be shown during the period of class introduction in order to stimulate students' interest. Take sophomore students in our college as an example, the first volume of the third edition of New Horizon College English Reading is used as their reading textbook and the title for the first unit is "Love without Limitations". This unit aims at guiding students to define and connotate "love" by discussion. The author introduced William Butler Yeats's well-known poem "When you are old" and asked students to appreciate both English and Chinese versions, and then expressed their understanding about love. Because the Chinese translation of this poem is widely spread in China and one Chinese song of the same name is also popular, so students were eager to read the English poem. On the basis of understanding the main idea, they did not feel too difficult for appreciating English poetry in class. Many students took down famous sentences in the poem. After class, they searched online to find some reading versions for pronunciation imitation and sent their reading to the class WeChat group and then commented on each other. The combination of literary elements and reading materials not only activates the learning atmosphere and helps teachers smoothly transit to reading text, but also encourages college students to actively explore more both in and after class [5]. For example, some students read another well-known poem about romantic love-"Oh, My Love is Like a Red, Red Rose" written by Scottish poet Robert Burns. They conducted research on the Romantic movement in the 18th and 19th century and the history of Scotland. That is a good opportunity for students to experience research-based learning in English study according to their own interests.

Appropriate introduction of literary background knowledge in college English class can also help students deepen their understanding of the text, cultivate critical thinking and gain profound life experience. "Choose to Be Alone on Purpose" in the fifth unit of the fourth book of New Horizon College English tells about the life philosophy originating from American transcendentalism. "Loneliness" seems like a very simple word in the text, but in fact it hides profound meaning between the lines. Transcendentalism is a philosophical movement which developed in the late 1820s and 1830s in the eastern United States. Its core point is to advocate that people can transcend feelings and reason and thus directly understand the truth, emphasizing the importance of intuition. In order to help students understand the cultural connotation of "choosing loneliness" in the text, the author selected some paragraphs from Henry David Thoreau's Walden, a representative of American transcendentalism, and led students to analyze the simple lifestyle that Thoreau advocates. Since a lot of students have read some paragraphs from Chinese translation version in high school, they were more familiar with Thoreau's idea in Walden than that in the reading text. So, the integration of Walden not only helped them understand the life philosophy more easily but also encouraged them to develop critical thinking around the theme of "simple life". The students also mentioned its connection with minimalist life which was a frequently discussed topic among young generations and shared their opinions in class.

In addition to reading class, literature can be used in oral English teaching. The third unit of the third book of the New Vision College English Listening and Speaking Textbook focuses on cultural differences between China and the West, such as Western individualism and Eastern collectivism. Before the class, the author arranged the students to read Lin Yutang's My Country and My People in different groups, and in the oral class led them to explore Eastern collectivism based on Lin's summary of Chinese personality. Literary education is not limited to English classrooms but should be integrated into the students' life as it will influence the students' thinking patterns in a subtle way.

\section{Design Teaching Activities Related to Literature and Establish a Long-Term Reading Evaluation Mechanism}

The traditional classroom teaching is based on the teacher's "teaching" with the students always passively accepting, and the test results are regarded as the main indicators of teaching evaluation [6]. With the integration of literature into college English teaching, teachers can add a literary reading part to the test evaluation system, design a variety of activities related to literature and aid students to go through basic research processes, thus eventually establish a long-term reading evaluation mechanism and evaluate and feedback students' 
reading tasks. For instance, students can be encouraged to rewrite classic excerpts into dialogues and even scripts for speaking performances in groups. Cuseo emphasizes the effects of cooperative learning as a teaching theory and strategy system in higher education, which is based on students' group work [2]. By inviting students to participate in study activities related to English literature, teachers are able to put the theory of cooperative learning into the practice and establish a new type of effective student-centered teaching model for college English education. Dubbing film clips adapted from famous works and trying creative writing such as creating various endings of stories or composing poems are effective ways to evaluate teaching quality, as well. These activities can fully mobilize students' enthusiasm for English learning so that they are able to feel and use authentic language and deepen their understanding of literary works. Good reading and writing habits can also be developed and strengthened in the process and students' ability to appreciating humanistic works and using English for communication can finally be cultivated.

Furthermore, research-based learning strategy can be practiced while students are doing literature-related tasks. Since undergraduates, especially freshmen and sophomores, do not have many opportunities to do academic research, so getting some hands-on experience about the basic process of conducting research lays a good foundation for students' academic study in the future. Necessary skills such as searching information in databases, reading English essays and using software to analyze data can be learned and trained in literature-related teaching activities. Taking one of the sophomore classes as an example, the students designed questionnaires based on their reading list and wrote English reports on the data as part of the reading examination. Divided into different groups, they first did a literature review and identified research purpose and questions by discussion, and designed questionnaires with the help of English teacher. When questionnaires were returned, then they did research and went through basic processes of data collection and analysis independently. Through group discussion, the students eventually reached out to their own conclusion and worked together to draft reports on the questionnaires. By participating in learning activities in a similar way to that in scientific research, college students can get experience in basic research processes and develop problem-solving abilities with the help of English teacher.

\section{CONCLUSION}

Literature is an important carrier of culture and an important manifestation of national personality. It is an effective teaching method to understand British and American culture through English and American literature and prepare students for intercultural communication. Literature has more significant value in developing research-based learning strategy, practicing critical thinking patterns and promoting humanistic spirit. Confronted by the situation that language skill training has dominated college English class in China, both universities and teachers should recognize the importance of literary education. As college English teachers, we should take the initiative to integrate English and American literature reading into the college English classroom in order to help students appreciate and understand the brilliant cultural achievements of human beings, cultivate reading habits and practice researchbased learning method. For example, college English teachers can recommend classics which meet student's English abilities, appropriately combine college English textbooks with literary elements and design teaching activities related to literature and establish a long-term reading evaluation mechanism. As Zhang Longxi says in "Teaching English in China: Language, literature, culture, and social implications”, to develop a culture of reading beyond one's discipline and specialty is very important in higher education. "To cultivate a sense of intellectual curiosity among our students, and to encourage them to explore issues in East-West comparative studies not superficially, but with real depth and thorough understanding" is English teachers' major task [8].

\section{REFERENCES}

[1] Brumfit, C. J. and R. Carter, Literature and Language Teaching. Shanghai: Shanghai Foreign Language Education Press, 2002.

[2] Cuseo J, "Collaborative \& Cooperative Learning in Higher Education: Proposed Taxonomy", Cooperative Learning and College Teaching, vol 2, 1992, pp. 54-72.

[3] Harmer J, The Practice of English Language Teaching. Harlow: Longman, 1991.

[4] Li Zhengshuan and Wang Huimin, "Due Awareness of Literary Education in College English Teaching", Contemporary Foreign Languages Studies, vol 3, 2013, pp. 38-42. (In Chinese)

[5] Long and Crookers, “Task-based Syllabus Design”, TESEL Quarterly, vol 26, 1991, pp126.

[6] Prebhu, Second Language Pedagogy. Oxford: Oxford University Press, 1987.

[7] Stern, H. H., Issues and Options in Language Teaching. Oxford: Oxford University Press, 1996.

[8] Zhang Longxi, "Teaching English in China: Literature, Culture and Social Implications”, Foreign Language Teaching and Research, vol 5, 2006, pp.248-54. 